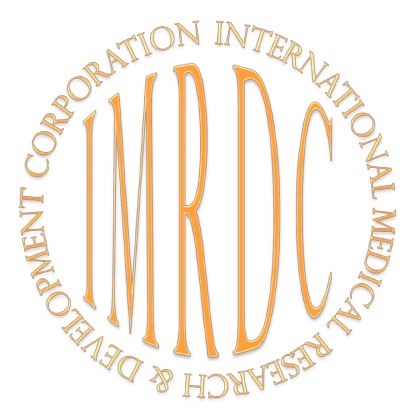

\title{
Non-specific Adaptive Reactions of Athletes: Evaluation and Correction
}

\author{
K. N. Naumova ${ }^{1}$; V.V. Anshakova ${ }^{1}, \mathrm{PhD} ;$ B. M. Kershengolts ${ }^{2}$ \\ ${ }^{1}$ North-Eastern Federal University \\ 2Institute of Biological Problems of Cryolithozone SB of the RAS \\ Yakutsk, the Republic of Sakha, Russia
}

\begin{abstract}
This work studies changes in non-specific adaptive reactions (NSAR) of athletes who practice Wushu and Qigong and take Kladorod, a biological product made from plant material. The results of our study demonstrate the effectiveness of Kladorod as a remedy to enhance adaptive capacity with the possibility of application for training of athletes without any restrictions within the criteria of doping control. (Int J Biomed. 2015;5(4):238-239.)
\end{abstract}

Keywords: non-specific adaptive reactions; sport; biocomplexes; mechanochemistry; lichens; salidroside.

\section{Introduction}

The physical state of an athlete can be reliably determined by blood test. According to results, we can reveal different types of NSAR: positive - stable and robust activation of training; transitional - unstable practice and unsustainable activation; negative - stress and reactivation.

The reactions of "training" and "activation" of high levels of reactivity are the most common physiological reactions, constituting the basis of non-specific health standards.

At the present stage of development of the sports, pharmacological support is one of the most popular tools for enhancing adaptive capacity and retention of an athlete in positive NSAR. For this purpose a biological product, Kladorod, which is based on a mechanically activated, ultrafine powder mixture of the lichen thalli of Cladonia and the roots and rhizomes of Rhodiola rosea, was designed [1]. In our earlier studies, it was found that taking a biological product it was found that taking a biological product according to a specific regimen increases its efficiency [2].

The aim of this study was to determine the criteria of disadaptation changes in athletes before and after taking Kladorod.

*Corresponding authors: Vera V. Anshakova, PhD. NorthEastern Federal University, the Republic of Sakha, Russia. E-mail: anshakova_v@mail.ru

\section{Material and Methods}

Twenty six sportsmen from the Wushu and Qigong Center "Heavenly River" of the Republic of Sakha (Yakutia), with various sports qualifications and aged between 20 and 43 , were given 4 Kladorod capsules a day for one month. A general blood test was performed on the hematology analyzer Abacus. The definition of the NSAR phase was estimated by the method of L.H. Garkavi [3].

Statistical analysis was performed using the statistical software «Statistica» (v6.0, StatSoft, USA). Baseline characteristics were summarized as frequencies and percentages for categorical variables. Group comparisons with respect to categorical variables are performed using chisquare tests or, alternatively, Yates' $\chi^{2}$ when expected cell counts were less than 5. A probability value of $P<0.05$ was considered statistically significant.

The study was conducted in accordance with ethical principles of the Declaration of Helsinki and approved by the North-Eastern Federal University Ethics Committee. Written informed consent was obtained from all participants.

\section{Resilts}

The features of phase changes the NSAR of athletes engaged in Wushu and Qigong while taking Kladorod (Group $1, \mathrm{n}=10)$ and those taking mechanically activated roots and rhizomes of Rhodiola rosea (Group 2, n=8), compared to those taking a placebo (Group 3, $\mathrm{n}=8$ ), are shown in Table 1 . 
Table 1.

The features of the NSAR phase changes

\begin{tabular}{|c|c|c|c|c|c|c|c|c|}
\hline \multirow[t]{2}{*}{ Group* } & \multicolumn{6}{|c|}{ NSAR type } & \multicolumn{2}{|c|}{ Yates' $\chi 2, P$} \\
\hline & \multicolumn{2}{|c|}{$\begin{array}{l}\text { Negative } \\
\mathrm{n}(\%)\end{array}$} & \multicolumn{2}{|c|}{$\begin{array}{c}\text { Transitional } \\
\mathrm{n}(\%)\end{array}$} & \multicolumn{2}{|c|}{$\begin{array}{c}\text { Positive } \\
\text { n (\%) }\end{array}$} & BAR & ARA \\
\hline Group 1 & $3(30)$ & $1(10)$ & $2(20)$ & $2(20)$ & $5(50)$ & $7(70)$ & $\begin{array}{l}\chi 2=0.938 \\
P=0.625\end{array}$ & $\begin{array}{c}\chi 2=6.338 \\
P=0.04\end{array}$ \\
\hline Group 2 & $2(25)$ & 0 & $3(37.5)$ & $5(62.5)$ & $3(37.5)$ & $3(37.5)$ & $\begin{array}{l}\chi 2=0.047 \\
P=0.977\end{array}$ & $\begin{aligned} \chi 2 & =4.547 \\
P & =0.103\end{aligned}$ \\
\hline Group 3 & $1(12.5)$ & $2(25)$ & $3(37.5)$ & $4(50)$ & $4(50)$ & $2(25)$ & $\begin{array}{l}\chi 2=1.172 \\
P=0.556\end{array}$ & $\begin{array}{l}\chi 2=0.422 \\
P=0.809\end{array}$ \\
\hline
\end{tabular}

*The groups were matched for age and sex. BRA -before remedy application, ARA -after remedy application

The data obtained can be explained by the fact that the lichen $\beta$-oligosaccharides in the composition of Kladorod, binding the Rhodiola rosea salidroside, form a unique complex that provides a higher digestibility of an active ingredient of Rhodiola rosea, increasing 5 to 10 times its bioavailability. The results of our study allow us to conclude that Kladorod leads to increasing the proportion of athletes with the positive types of NARO, compared to pure Rhodiola, which demonstrates the higher effectiveness of Kladorod as a remedy to enhance adaptive capacity with the possibility of application for training of athletes without any restrictions within the criteria of doping control.

\section{References}

1. Anshakova VV. The mechanochemical technology for producing of biocomplexes based on lichen material. Int $\mathrm{J}$ Biomed. 2012; 3:232-236.

2. Anshakova VV. Increase activity of pharmaceutical substance lichens $\beta$-oligosaccharides. Russ J Biopharmaceut. 2012; 4(4):42-46.

3. Garkavi LH, Kvakina EB, Kuzmenko TS. Antistress reactions and activation therapy. The reaction of activation as a way to health through self-organization processes. M.: IMEDIS, 1998. 